Article

\title{
Development, Optimization, and Comparison of Different Sample Pre-Treatments for Simultaneous Determination of Vitamin $\mathrm{E}$ and Vitamin $\mathrm{K}$ in Vegetables
}

\author{
Antonella Aresta ${ }^{1}{ }^{1}$, Gualtiero Milani $^{2}$, Maria Lisa Clodoveo $\left.{ }^{3}{ }^{(}\right)$, Carlo Franchini ${ }^{2}$, \\ Pietro Cotugno ${ }^{1}$, Ivana Radojcic Redovnikovic ${ }^{4}$, Maurizio Quinto ${ }^{5}$ (D), Filomena Corbo ${ }^{2, *(D)}$ and \\ Carlo Zambonin ${ }^{1}$ (D) \\ 1 Department of Chemistry, University “Aldo Moro”, Bari Via E. Orabona, 4, I-70125 Bari, Italy; \\ antonellamaria.aresta@uniba.it (A.A.); pietro.cotugno@uniba.it (P.C.); carlo.zambonin@uniba.it (C.Z.) \\ 2 Department of Pharmacy-Pharmaceutical Sciences, University “Aldo Moro", Bari Via E. Orabona, 4, \\ I-70125 Bari, Italy; gualtiero.milani@uniba.it (G.M.); carlo.franchini@uniba.it (C.F.) \\ 3 Interdisciplinary Department of Medicine, University “Aldo Moro", Bari Pz G. Cesare 11, Policlinico di Bari, \\ 70124 Bari, Italy; marialisa.clodoveo@uniba.it \\ 4 Faculty of Food Technology and Biotechnology, University of Zagreb, Pierottijev 6, 10000 Zagreb, Croatia; \\ irredovnikovic@pbf.hr \\ 5 Department of Agricultural Food and Environmental Sciences, University of Foggia, Via A.Gramsci 89/91, \\ 71122 Foggia, Italy; maurizio.quinto@unifg.it \\ * Correspondence: filomena.corbo@uniba.it; Tel.: +39-0805442746
}

Academic Editor: Ryszard Amarowicz

Received: 12 May 2020; Accepted: 26 May 2020; Published: 28 May 2020

check for updates

\begin{abstract}
The absence of vitamin E from the diet can lead to cardiovascular disease, cancer, cataracts, and premature aging. Vitamin K deficiency can lead to bleeding disorders. These fat-soluble vitamins are important nutritional factors that can be determined in different methods in vegetables. In this work, the simultaneous determination of $\alpha$-tocopherol, $\alpha$-tocopheryl acetate, phylloquinone, and menaquinone- 4 by gas chromatography-mass spectrometry (GC-MS) has been optimized using both direct injection and solid phase microextraction (SPME). Three different sample pre-treatment approaches based on: (A) solid-liquid-liquid-liquid extraction (SLE-LLE), (B) SLE, and (C) SPME were then applied to extract the target analytes from vegetables samples using menaquinone as internal standard. All the procedures allowed the determination of the target analytes in onion, carrot, celery, and curly kale samples. Similar results were obtained with the three different approaches, even if the one based on SPME offers the best performance, together with a reduced use of solvent, time consumption, and experimental complexity, which makes it the preferable option for industrial applications.
\end{abstract}

Keywords: SPME; GC-MS; $\alpha$-tocopherol; $\alpha$-tocopheryl acetate; phylloquinone; menaquinone-4; vegetables

\section{Introduction}

The determination of natural products of interest to human health (bioactive compounds) is carried out through a complex workflow that generally includes many steps such as extraction, fractionation, separation, and isolation of the compounds. However, the complex nature of natural extracts and low levels are often an obstacle to their correct determination.

The traditional strategies to isolate bioactive compounds from vegetables are based on liquid-liquid extraction (LLE), solid-liquid extraction (SLE), or solid phase extraction (SPE) using solvents of different 
polarity. The first two are very useful techniques for isolating, pre-concentrating and transferring analytes in a phase that is compatible with the analytical instrument. These extraction techniques are based on passive diffusion principle through the interface between the two phases, the extraction times are linked to interfacial contact, generally a greater agitation determines a reducing of times. The increase in stirring speed simultaneously increases the risk of forming emulsions which will in turn require centrifugation, filtration or addition of other solvent or substances to disrupt the emulsion. SPE requires a lower use of organic solvent and is based on systems such as: cartridges, columns, or membranes containing an extractive absorbent. The sample is inserted into the cartridge and all the matrix interferences that have been adsorbed are washed by a weak solvent and the elution of the analytes is done using a small amount of the appropriate solvent [1]. The crucial factors to apply these analytical techniques are the choice of the solvent linked to the affinity for analytes, the toxicity, the selectivity, the volatility, and finally the price, which must not be underestimated.

The search for fast, efficient, cost effective, and environment friendly methods of analysis prompted the introduction in 1989 of Solid Phase Microextraction (SPME) by J. Pawliszyn [2]. This technique compared to conventional ones is faster, simpler, sensitive and is fully eco-sustainable by requiring only water for the extraction. Since the invention of the technique until today, its applications have dramatically increased. Therefore, to date, its applications are numerous, and include the determination of natural products present in trace in drinking, fruits and organic samples [2]. Finally, dispersive solid phase extraction (d-SPE) analysis is a simple and straightforward sample preparation technique suitable for a wide variety of food and agricultural products. One specific method which has become popular is the QuEChERS (Quick, Easy, Cheap, Effective, Rugged e Safe) technique which was created to facilitate the rapid screening of large numbers of food and agricultural samples for pesticide residues.

It could be a valid alternative to SPME, but according to our knowledge it is not among the methods of choice for the determination of fat-soluble vitamins.

In the light of these considerations, in this paper, the SPME has been chosen for the scope of the experimental work described in this paper that aims to develop a rapid, sensitive, and specific analytical method for the simultaneous determination of fat-soluble vitamins $\mathrm{E}$ and $\mathrm{K}$ in food and biological matrices.

Fat-soluble vitamins $\mathrm{E}$ and $\mathrm{K}$ are important nutritional factors and their determination can be useful for nutraceutical, nutrigenomics, and nutribolomics studies. The absence of vitamin E from the diet can lead to cardiovascular disease, cancer, cataracts, and premature aging [3,4]. Vitamin K deficiency can lead to bleeding disorders [5]. Humans and animals do not synthesize Vitamin E, thus, $\alpha$ - tocopherol, according to Directive N. 95/2/EC (1995) of the European Parliament, is an official food additive or dietary supplement. The importance of Vitamin $\mathrm{E}$ is also documented by a specific Health Claim [6-8] approved by the EFSA (European Food Safety Authority) that can be used to label functional foods with a high healthy value, e.g., extra virgin olive oil rich with Vitamin E.

Tocopheryl acetate (vitamin E acetate) is the ester of acetic acid and tocopherol is mainly used in dermatological products. Vitamin $\mathrm{K}$ includes different compounds that are characterized by a naphthoquinone ring and a different aliphatic side chain that define Vitamin K1 (phylloquinone) and Vitamin K2 (menaquinones). Phylloquinone is made by plants, mostly green leafy vegetables, and is widely used as supplement to treat certain bleeding disorders $[5,9,10]$. To date, the determination of $\alpha$ - tocopherol, tocopheryl acetate, phylloquinone, and menaquinones has been only accomplished separately. Historically, vitamin E was considered difficult to measure because of its instability and its lipophilicity, but these challenges have largely been overcome with modern technologies [11].

Existing methods for the determination of vitamins in food are mainly based on traditional extraction techniques, mainly solid phase extraction (SPE), followed by chromatographic analysis [12-14]. Pressurized liquid extraction (PLE) and dispersive liquid-liquid microextraction (DLLME) were also used to isolate and preconcentrate tocopherols and tocotrienols from plant foods [15]. A good, simple, and inexpensive alternative has been proposed by Aresta et al. based SPME 
coupled to GC-MS for the determination of $\alpha$-tocopherol in olive oil as other important bioactive compound in different food matrix [16-19].

A fast and simple method for the determination of vitamins, including vitamin E acetate, in infant formula by DLLME combined with HPLC-UV has been also recently reported [20]. Very recently, an overview of methods for assessment of vitamin K has been provided by Górska [21]. Existing methods are usually laborious and there is still a great need for the development of robust, reliable methods for the quantitative determination of vitamin K. For instance, SPE-LC approaches were proposed for the determination of Vitamin K1 in fish feeds and shrimp post larvae [22] and edible microgreens [23] while DLLME coupled to liquid chromatography with diode-array and ESI (Electrospray ionization)-mass spectrometry detection (proved to be useful for routine control analysis of vitamins D and $\mathrm{K}$ in different food commodities [24]. Lately, two approaches based on liquid and solid phase extraction followed by ultra-high-performance liquid chromatography-atmospheric pressure chemical ionization tandem mass spectrometric (UHPLC-APCI-MS/MS) and liquid chromatography-with diode array-fluorescence detector (HPLC-DAD-FLD) were successfully developed for the determination of eight vitamin K compounds in 17 fermented food products at micrograms level [25] and of tocols, $\gamma$-oryzanols, phytosterols, squalene, cholecalciferol, and phylloquinone in rice bran and vegetable oil samples [26], respectively. A faster method for the determination of vitamin $\mathrm{K}$ in leaves was based on SPME-GC-FID using a polydimethylsiloxane (PDMS) fiber [27].

In the light of these considerations in the present work, the task of the simultaneous determination of $\alpha$-tocopherol, $\alpha$-tocopheryl acetate, phylloquinone and menaquinone by gas chromatography-mass spectrometry has been addressed. Three different sample pre-treatment approaches, of which the first two based on conventional extraction techniques and the third on SPME, were applied to extract the target analytes from vegetables samples (onion, carrot, celery, and curly kale) using menaquinone as the internal standard. All of the procedures permitted the determination of the target analytes in the selected food at satisfactory LODs, limits of detection, even if SPME proved to be the simpler and faster approach.

\section{Results}

\subsection{Vegetable Samples}

All samples (onion, carrot, celery, and curly kale) were of local origin and collected from supermarkets. Each vegetable was finely grated and immediately subject to extraction procedures or dried for preservation. In this regard, the grated sample was portioned into aliquots $(0.5 \mathrm{~g})$ that were dried in a CHRIST-vacuum concentrator (Centrifuge Concentrator Centrifuge) (RVC 2-18, Osterode am Harz, Germany) at $30{ }^{\circ} \mathrm{C}$ until reduced to $43 \% \pm 1 \%$ their weight. Dry residues were stored at $8{ }^{\circ} \mathrm{C}$ in the dark until analyzed. Spiked samples were prepared in triplicate by adding suitable amounts of standard solutions to fresh or dry aliquots.

\subsection{Programmed Temperature Vaporization (PTV) and GC Parameter Optimization Using Direct Injection}

The method was initially developed working in direct injection $(1 \mu \mathrm{L})$ mode. Initially, the parameters of the PTV injector were optimized. The low starting temperature $\left(70{ }^{\circ} \mathrm{C}\right)$ avoided the overflow of the liner with solvent vapors, the heating rate $\left(14.5^{\circ} \mathrm{C} / \mathrm{s}\right)$ and the splitless time of 1 min optimized the transfer of the analytes into the column, the final temperature $\left(300^{\circ} \mathrm{C}\right)$ assured the cleaning of the inlet. The chromatographic conditions were then optimized to achieve good separation and chromatographic efficiency. The GC-MS chromatogram was obtained by directly injecting a standard of $\alpha$-tocopherol, $\alpha$-tocopheryl acetate, phylloquinone, and menaquinone- 4 at a concentration level of $50 \mu \mathrm{g} \mathrm{mL}{ }^{-1}$ using the optimized temperature gradient program and shows its resolution capability as reported in Figure 1. Calibration curves were linear in the explored concentration range with correlation coefficients greater than 0.999 and intercepts significantly close to zero at the $95 \%$ confidence level. The within-day $(n=5)$ and between-days ( $n=5$ over 5 days) coefficients of variation, 
estimated by an ANOVA test, ranged from 2.8 ( $\alpha$-tocopherol) to 4.0 (menaquinone) \% and from 3.4 ( $\alpha$-tocopherol) to 5.9 (menaquinone) \%, respectively, and remained practically unchanged at 5 and $50 \mu \mathrm{g} \mathrm{mL}{ }^{-1}$. The limit of detection (LOD) and limit of quantification (LOQ) were calculated as three and ten-fold the standard deviation of the intercept of the calibration curves. The estimated LODs were in the ranges 0.1 ( $\alpha$-tocopherol and $\alpha$-tocopherol acetate) $-0.6 \mu \mathrm{g} \mathrm{mL}{ }^{-1}$ (menaquinone-4), respectively, while LOQs were in the range 0.4 ( $\alpha$-tocopherol)-1.9 $\mathrm{g} \mathrm{mL}^{-1}$ (menaquinone-4), respectively. All the validation parameters are resumed in Table 1 . The within day and between days RSD\% were always better than 4.0 and 5.9 , respectively.

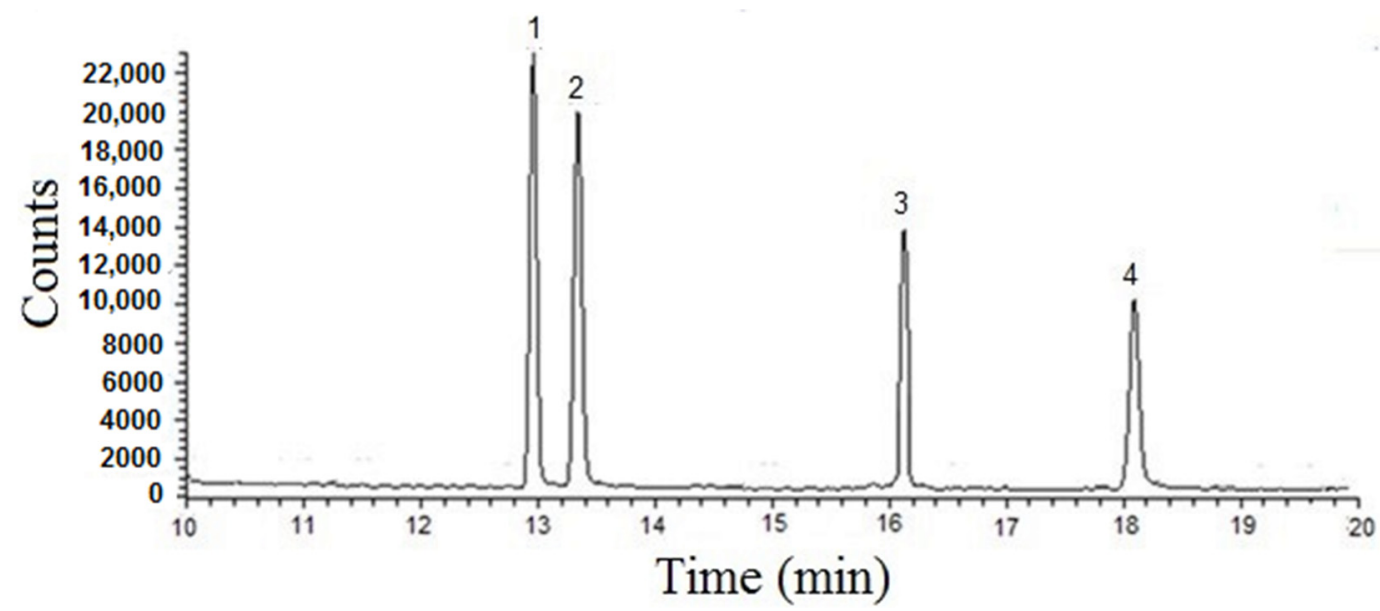

Figure 1. Gas chromatography-mass spectrometry (GC-MS) chromatogram obtained directly injecting a standard solution of $\alpha$-tocopherol (1), $\alpha$-tocopheryl acetate (2), phylloquinone (3), and menaquinone- 4 (4) at a concentration level of $50 \mu \mathrm{g} \mathrm{mL} \mathrm{m}^{-1}$.

Table 1. Linear range, detection limits and precision of $\alpha$-tocopherol, $\alpha$-tocopherol acetate, phylloquinone, and menaquinone- 4 obtained by direct injection.

\begin{tabular}{|c|c|c|c|c|c|c|}
\hline Analyte & $\begin{array}{l}\text { Linearity Range } \\
\quad\left(\mu \mathrm{g} \mathrm{mL}^{-1}\right)\end{array}$ & $\mathbf{R}^{2}$ & $\begin{array}{c}\text { LOD } \\
\left(\mu \mathrm{g} \mathrm{mL}^{-1}\right)\end{array}$ & $\begin{array}{c}\mathrm{LOQ} \\
\left(\mu \mathrm{g} \mathrm{mL} \mathrm{mL}^{-1}\right)\end{array}$ & $\begin{array}{c}\text { Within-Day } \\
(\text { RSD\%, } n=3)\end{array}$ & $\begin{array}{c}\text { Between-Days } \\
(\text { RSD } \%, n=15)\end{array}$ \\
\hline$\alpha$-tocopherol & $0.4-100$ & 0.999 & 0.1 & 0.4 & 2.8 & 3.4 \\
\hline $\begin{array}{l}\alpha \text {-tocopherol } \\
\text { acetate }\end{array}$ & $0.4-100$ & 0.999 & 0.1 & 0.4 & 2.9 & 3.6 \\
\hline Phylloquinone & $0.7-100$ & 0.999 & 0.2 & 0.7 & 3.9 & 4.4 \\
\hline Menaquinone & 1.9-100 & 0.999 & 0.6 & 1.9 & 4.0 & 5.9 \\
\hline
\end{tabular}

\subsection{SPME Procedure Optimization}

Experiments were then devoted to the optimization of the SPME conditions and to the validation of the method using SPME. A 7- $\mu$ m thick PDMS-coated fiber was chosen for the simultaneous extraction of the selected vitamins from aqueous solutions since it has been successfully employed $[17,26,27]$ for the extraction of $\alpha$-tocopherol, vitamin K1 and KIt was also reported that the moderate addition of ethanol in water increases the solubility of the analytes [28] due to lower hydrophobic repulsion between ethanol and vitamin molecules, while the addition of $\mathrm{HCl}(10 \mathrm{mM})$ to the water-ethanol mixture $[17,29]$ has a positive effect on the extraction of $\alpha$-tocopherol with the PDMS fiber. Thus, the effect of the addition of ethanol and $\mathrm{HCl}$, respectively, on the extraction efficiency were evaluated. Figure 2 reports how the extraction efficiency was affected by the addition of varying concentrations of ethanol and $\mathrm{HCl}(10 \mathrm{mM})$. While the addition of $10 \%$ ethanol has a positive effect on the extraction of all the analytes, a further increase in its concentration $(20 \%)$ produced opposite results, i.e., response increase for the more hydrophobic vitamins $\mathrm{E}$ and response decrease for vitamins $\mathrm{K}$. The addition of $\mathrm{HCl}$ shows rather positive results for all the investigated compounds. Consequently, a concentration of $10 \%$ ethanol with the presence of $\mathrm{HCl}(10 \mathrm{mM})$ was used for further experiments. Usually, salt addition 
increases the ionic strength of the solution and the organic compounds become less soluble increasing the partition coefficients between the phases. Four different concentrations of $\mathrm{NaCl}(0,10 \%, 20 \%$, and $30 \%$ ) in water with $10 \%$ ethanol and $10 \mathrm{mM} \mathrm{HCl}$ were tested and the relevant results in terms of extraction efficiency are shown in Figure 2. It was apparent, in agreement with Aresta et al. [17,29] but in contrast with [27] that the extraction efficiency for all the analytes was negatively affected by salt addition and was not further investigated.

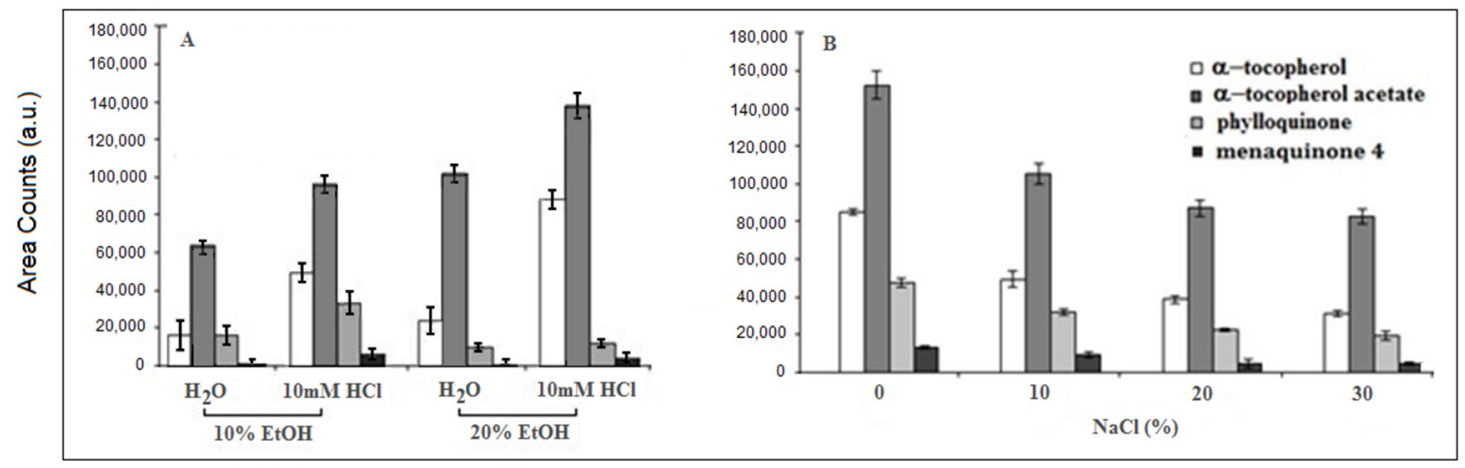

Figure 2. Effects of ethanol and $\mathrm{HCl}(\mathbf{A})$ and of $\mathrm{NaCl}(\mathbf{B})$ on the solid phase microextraction (SPME) efficiency.

As far as the extraction volume is concerned, $15 \mathrm{~mL}$ was selected as optimal value, since it was found that lower volumes produced a response decrease for all the analytes, while no effects were observed using higher volumes. Figure 3 shows the extraction time profiles obtained on Vitamins E and $\mathrm{K}$ at the temperature of 20 and $50{ }^{\circ} \mathrm{C}$, respectively. The equilibrium conditions were almost always reached after $30 \mathrm{~min}\left(50^{\circ} \mathrm{C}\right)$ and $40 \mathrm{~min}\left(20^{\circ} \mathrm{C}\right)$ of extraction and the higher extraction efficiencies were obtained at $50^{\circ} \mathrm{C}$ for all the analytes except for $\alpha$-tocopherol that showed a significant response decrease and, according to the literature $[17,29]$ never reached equilibrium conditions. The extraction time of $30 \mathrm{~min}$ and the temperature of $50{ }^{\circ} \mathrm{C}$ were selected for the following experiments. The desorption temperature should be high enough to ensure the complete desorption of the extracted compounds from the fiber coating. In the present work, desorption was carried out for $5 \mathrm{~min}$ at $300{ }^{\circ} \mathrm{C}$, since a significant "carry-over" was observed when desorbing at lower temperatures or shorter desorption times. The method was validated using the optimized SPME conditions and the relevant results are reported in Table 2. The dynamic range of the developed SPME-GC-MS procedure resulted in linear from the LOQ values for over two orders of magnitude, with correlation coefficients better than 0.997 and intercepts not significantly different from zero at $95 \%$ confidence level. The within day and between days RSD\% were always better than 4.8 and 8.8, respectively. The estimated LOD and LOQ, calculated as three and ten-fold the standard deviation of the intercept of the calibration curves, were always better than 10 and $40 \mathrm{ng} \mathrm{mL}^{-1}$, respectively.

Table 2. Linear range, detection limits and precision of $\alpha$-tocopherol, $\alpha$-tocopherol acetate, phylloquinone, and menaquinone- 4 obtained by SPME.

\begin{tabular}{|c|c|c|c|c|c|c|}
\hline Analyte & $\begin{array}{l}\text { Linearity Range } \\
\left(\mu \mathrm{g} \mathrm{mL}^{-1}\right)\end{array}$ & $\mathbf{R}^{2}$ & $\begin{array}{c}\text { LOD } \\
\left(\mu \mathrm{g} \mathrm{mL}^{-1}\right)\end{array}$ & 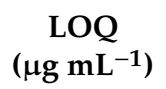 & $\begin{array}{c}\text { Within-Day } \\
(\text { RSD } \%, n=3)\end{array}$ & $\begin{array}{l}\text { Between-Days } \\
(\text { RSD } \%, n=15)\end{array}$ \\
\hline$\alpha$-tocopherol & $0.004-1.0$ & 0.9999 & 0.001 & 0.004 & 4.3 & 8.8 \\
\hline $\begin{array}{l}\alpha \text {-tocopheryl } \\
\text { acetate }\end{array}$ & $0.006-1.0$ & 0.9999 & 0.002 & 0.006 & 4.8 & 7.5 \\
\hline phylloquinone & $0.036-5.0$ & 0.9999 & 0.011 & 0.036 & 4.7 & 8.0 \\
\hline menaquinone & $0.038-5.0$ & 0.9990 & 0.011 & 0.038 & 4.6 & 6.9 \\
\hline
\end{tabular}




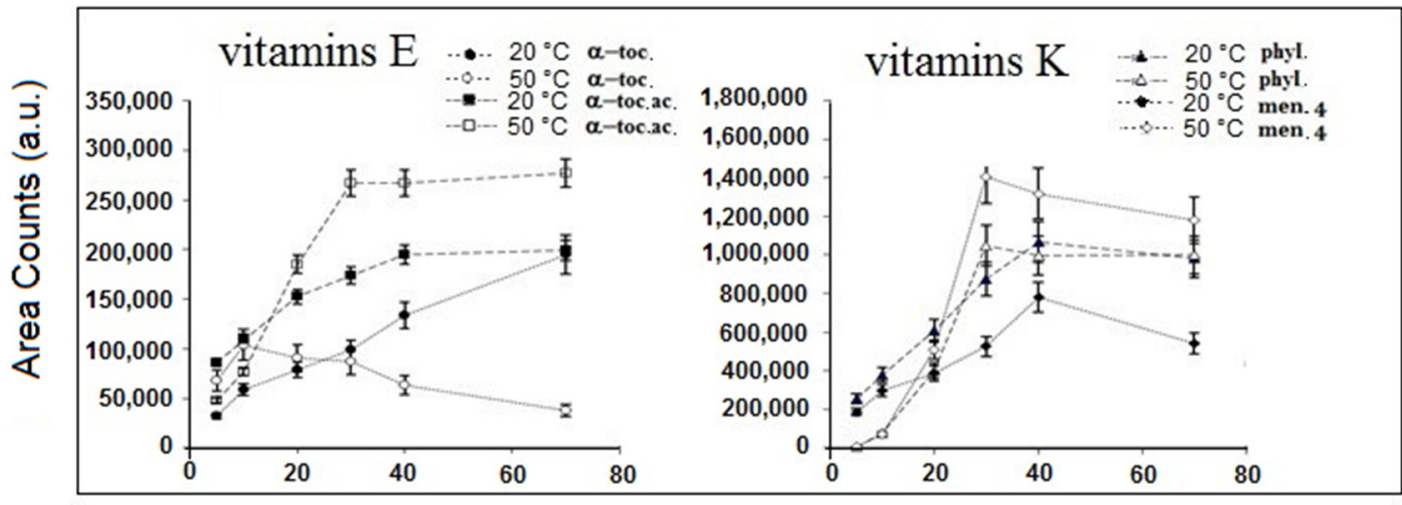

Time (min)

Figure 3. Extraction time profiles obtained on Vitamins $E$ and $K$ at the temperature of 20 and $50{ }^{\circ} \mathrm{C}$, respectively.

\section{Discussion}

The three sample pre-treatment approaches were applied on carrot, celery, curly kale, and onion for the simultaneous determination of $\alpha$-tocopherol, $\alpha$-tocopheryl acetate, and phylloquinone, using menaquinone- 4 as the internal standard, since it is known to be absent in these vegetables. Figure 4 reports, as an example, the GC-MS extracted-ion chromatograms of a carrot dry sample pre-treated with the three procedures (A, B, and C) optimized in this work. The insets show the spectra acquired in the samples compared to those of the NIST (National Institute of Standards and Technology) library. As apparent, all the described extraction procedures permitted the easy determination of all the analytes and the internal standard. Quantitation was performed with the standard addition method. Recovery studies were performed at the concentration levels of 5,50, and $100 \mu \mathrm{g} \mathrm{mL}^{-1}$ and the relevant results are shown in Table 3.

Table 3. Percentage recoveries obtained with the sample pretreatments A and B.

\begin{tabular}{ccccccc}
\hline Method & \multicolumn{3}{c}{ B } & B & \\
\hline [Vitamin] & {$[5]$} & {$[50]$} & {$[100]$} & {$[5]$} & {$[50]$} & {$[100]$} \\
$\left(\mu \mathrm{g} \mathrm{mL}^{-1}\right)$ & $\left(\mu \mathrm{g} \mathrm{mL}^{-1}\right)$ & $\left(\mu \mathrm{g} \mathrm{mL}^{-1}\right)$ & $\left(\mu \mathrm{gL} \mathrm{m}^{-1}\right)$ & $\left(\mu \mathrm{gL} \mathrm{mL}^{-1}\right)$ & $\left(\mu \mathrm{mL} \mathrm{m}^{-1}\right)$ \\
$\alpha$-tocopherol & $59 \pm 16 \%$ & $61 \pm 18 \%$ & $63 \pm 7 \%$ & $84 \pm 15 \%$ & $93 \pm 11 \%$ & $85 \pm 6 \%$ \\
$\alpha$-tocopheryl acetate & $55 \pm 7 \%$ & $58 \pm 10 \%$ & $60 \pm 6 \%$ & $83 \pm 18 \%$ & $77 \pm 6 \%$ & $80 \pm 7 \%$ \\
phylloquinone & $64 \pm 15 \%$ & $66 \pm 6 \%$ & $60 \pm 12 \%$ & $86 \pm 12 \%$ & $85 \pm 13 \%$ & $81 \pm 9 \%$ \\
menaquinone & $65 \pm 24 \%$ & $66 \pm 10 \%$ & $66 \pm 23 \%$ & $93 \pm 21 \%$ & $88 \pm 18 \%$ & $95 \pm 10 \%$ \\
\hline
\end{tabular}

SPME (C) was not considered in these experiments since it is notoriously a non-exhaustive technique. Recoveries were found to be concentration independent $(p<0.05)$ and procedure B provides the highest recoveries $(>80 \%)$. The matrix effect for the SPME procedure [30] was calculated as described in the experimental section, and the values were $69 \pm 15,80 \pm 12$ and $96 \pm 5$ for each dilution ratio (1:1 or $0.1: 1$ or $0.005: 1, w / v$, respectively). As apparent, the matrix effect was minimized working at the dilution ratio of 0.005:1. The optimized conditions are reported in the experimental section. The concentrations of the target vitamins were estimated in several fresh or dry samples; Table 4 reports, as an example, the results obtained in specific carrot, celery, curly kale and onion samples while Table 5 resumes the whole results reporting the concentration ranges found in all the samples. Finally, the accuracy of the SPME-GC-MS method was evaluated. Vitamins were added to each sample at twice the estimated concentrations or LOQs levels. The concentrations obtained were compared with expectations. The results were between 10 (menaquinone, carrot) and 3\% (phylloquinone, onion) with an average of $6.5 \% \pm 2.6 \%$. Accuracy corresponded to the acceptance criteria, because the deviations of the mean values from target values were always below $15 \%$. 
Table 4. Concentrations of the target vitamins estimated in specific carrot, celery, curly kale, and onion samples.

\begin{tabular}{|c|c|c|c|c|c|c|c|}
\hline \multirow{2}{*}{\multicolumn{2}{|c|}{ Vegetable }} & \multicolumn{6}{|c|}{ Analyte Concentration $\left(\mu g g^{-1}\right)$} \\
\hline & & \multicolumn{2}{|c|}{ [ $\alpha$-tocopherol] } & \multicolumn{2}{|c|}{ [ $\alpha$-tocopheryl acetate] } & \multicolumn{2}{|c|}{ [phylloquinone] } \\
\hline \multirow{5}{*}{$\begin{array}{l}\text { Pre-treatment } \\
\text { celery }\end{array}$} & & fresh & dry & fresh & dry & Fresh & dry \\
\hline & A & $14.5 \pm 1.4$ & $32.0 \pm 1.1$ & $2.4 \pm 0.4$ & $6.0 \pm 0.4$ & 2.6 & $8.1 \pm 0.1$ \\
\hline & $\mathrm{B}$ & $15.0 \pm 2.5$ & $30.6 \pm 9.1$ & nd & $5.9 \pm 0.6$ & nd & $7.8 \pm 0.1$ \\
\hline & $\mathrm{C}$ & $\begin{array}{c}19.3 \pm 1.1 \\
\text { fresh }\end{array}$ & $\begin{array}{c}47.9 \pm 3.8 \\
\text { dry }\end{array}$ & $\begin{array}{l}\text { nd } \\
\text { fresh }\end{array}$ & $\begin{array}{c}6.8 \pm 0.5 \\
\text { dry }\end{array}$ & $\begin{array}{c}\text { nd } \\
\text { Fresh }\end{array}$ & $\begin{array}{c}8.0 \pm 0.1 \\
\text { dry }\end{array}$ \\
\hline & A & $18.9 \pm 0.9$ & $32.8 \pm 9.4$ & $2.8 \pm 0.4$ & $4.7 \pm 0.2$ & $3.2 \pm 0.2$ & $8.0 \pm 0.6$ \\
\hline \multirow{3}{*}{$\begin{array}{l}\text { Pre-treatment } \\
\text { curly kale }\end{array}$} & $\mathrm{B}$ & $22.5 \pm 1.1$ & $46.1 \pm 8.2$ & $2.0 \pm 0.6$ & $4.9 \pm 0.3$ & $3.4 \pm 0.1$ & $8.6 \pm 0.5$ \\
\hline & C & $\begin{array}{c}20.0 \pm 0.9 \\
\text { fresh }\end{array}$ & $\begin{array}{c}50 \pm 1.2 \\
\text { dry }\end{array}$ & $\begin{array}{c}2.0 \pm 0.1 \\
\text { fresh }\end{array}$ & $\begin{array}{c}4.0 \pm 0.3 \\
\text { dry }\end{array}$ & $\begin{array}{c}\text { nd } \\
\text { fresh }\end{array}$ & $\begin{array}{c}8.8 \pm 0.7 \\
\text { dry }\end{array}$ \\
\hline & A & $17.9 \pm 1.0$ & $39.2 \pm 2.3$ & $1.9 \pm 0.6$ & $3.3 \pm 0.3$ & $6.9 \pm 0.6$ & $13.9 \pm 0.8$ \\
\hline \multirow[t]{2}{*}{ Pre-treatment } & $\mathrm{B}$ & $18.9 \pm 1.5$ & $43.6 \pm 7.6$ & $2.0 \pm 0.5$ & $3.8 \pm 1.3$ & $8.1 \pm 0.5$ & $13.5 \pm 0.6$ \\
\hline & $\mathrm{C}$ & $\begin{array}{c}20.6 \pm 1.2 \\
\text { fresh }\end{array}$ & $\begin{array}{c}35.2 \pm 2.2 \\
\text { dry }\end{array}$ & $\begin{array}{c}2.0 \pm 0.5 \\
\text { fresh }\end{array}$ & $\begin{array}{c}4.1 \pm 0.8 \\
\text { dry }\end{array}$ & $\begin{array}{c}9.3 \pm 0.8 \\
\text { fresh }\end{array}$ & $\begin{array}{c}14.6 \pm 1.1 \\
\text { dry }\end{array}$ \\
\hline onion & A & $4.9 \pm 1.1$ & $10.4 \pm 2.1$ & $2.2 \pm 0.6$ & $4.1 \pm 0.9$ & $3.0 \pm 0.9$ & $7.9 \pm 0.8$ \\
\hline \multirow[t]{2}{*}{ Pre-treatment } & $\mathrm{B}$ & $4.1 \pm 0.9$ & $11.5 \pm 2.0$ & $2.0 \pm 0.1$ & $4.7 \pm 0.5$ & $3.4 \pm 0.9$ & $8.5 \pm 0.9$ \\
\hline & $\mathrm{C}$ & $3.3 \pm 0.4$ & $10.9 \pm 1.1$ & $2.0 \pm 0.9$ & $4.3 \pm 0.9$ & nd & $9.0 \pm 1.1$ \\
\hline
\end{tabular}

nd $=$ not detectable

Table 5. Concentration ranges found for the selected analytes in all the selected samples using the three optimized sample pre-treatment approaches.

\begin{tabular}{|c|c|c|c|c|c|c|c|}
\hline \multirow{3}{*}{$\begin{array}{c}\text { Number Samples } \\
10\end{array}$} & \multirow{3}{*}{$\begin{array}{c}\text { Vegetable } \\
\text { carrot }\end{array}$} & \multicolumn{6}{|c|}{ Concentration Range $\left(\mu g g^{-1}\right)$} \\
\hline & & \multicolumn{2}{|c|}{ [ $\alpha$-tocopherol] } & \multicolumn{2}{|c|}{ [ $\alpha$-tocopheryl acetate] } & \multicolumn{2}{|c|}{ [phylloquinone] } \\
\hline & & fresh & dry & fresh & dry & fresh & dry \\
\hline & A & $6.1-44.3$ & $13.5-98.0$ & nd-20.2 & nd-50.5 & nd -2.6 & nd-8.1 \\
\hline \multirow[t]{2}{*}{ Pre-treatment } & $\mathrm{B}$ & $6.3-47.5$ & $13.0-97.5$ & nd-19.8 & nd-49.6 & nd-3.6 & nd-9.0 \\
\hline & C & $5.6-39.8$ & $13.9-98.8$ & nd-19.9 & nd-52.2 & nd-3.2 & nd-8.0 \\
\hline \multirow[t]{2}{*}{4} & celery & fresh & dry & fresh & dry & fresh & dry \\
\hline & A & $18.0-20.9$ & $32.0 \pm 44.4$ & nd-2.5 & nd-4.9 & nd-3.6 & nd-9.1 \\
\hline \multirow[t]{2}{*}{ Pre-treatment } & B & $17.8-22.5$ & $31.9-43.8$ & nd-2.7 & $\mathrm{nd}-4.8$ & nd-3.6 & nd-9.0 \\
\hline & C & $18.1-21.8$ & $32.1-45.0$ & nd-2.5 & nd -5.0 & nd -3.9 & nd-9.8 \\
\hline \multirow[t]{2}{*}{6} & curly kale & fresh & dry & fresh & dry & fresh & dry \\
\hline & A & $8.6-20.5$ & $18.0-43.1$ & nd-13.0 & nd-22.1 & nd -7.6 & nd -15.7 \\
\hline \multirow[t]{2}{*}{ Pre-treatment } & B & $8.9-19.8$ & $18.3-42.2$ & $2.0 \pm 0.5$ & nd-21.9 & nd-7.5 & nd-14.6 \\
\hline & C & $8.2-20.6$ & $19.5-43.6$ & $2.0 \pm 0.5$ & $4.1 \pm 0.8$ & nd -9.3 & nd -16.0 \\
\hline \multirow[t]{2}{*}{14} & onion & fresh & dry & fresh & dry & fresh & dry \\
\hline & A & $2.3-6.0$ & 5.1-14.6 & $\mathrm{nd}-8.1$ & nd-19.9 & nd-3.5 & nd-8.7 \\
\hline \multirow[t]{2}{*}{ Pre-treatment } & B & $2.0-5.6$ & $5.0-14.1$ & nd-8.0 & nd-20.3 & nd -3.6 & nd-9.0 \\
\hline & $\mathrm{C}$ & $2.1-6.3$ & $4.9-14.9$ & nd-7.9 & nd-19.7 & nd -3.5 & nd-9.5 \\
\hline
\end{tabular}



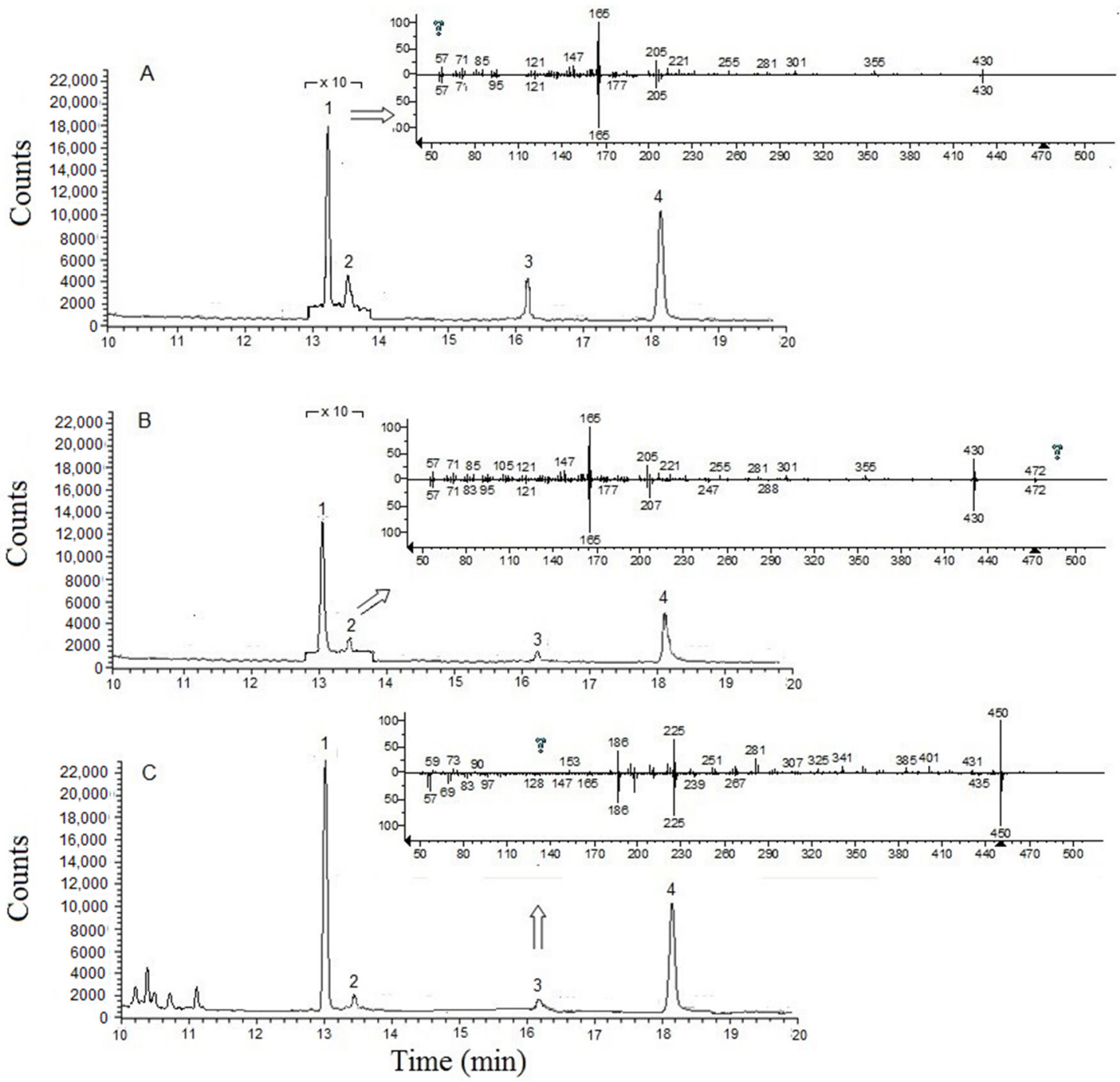

Figure 4. GC-MS extracted-ion chromatograms ( $m / z 165$ and 186) of a carrot dry sample extracted by the pre-treatment (A), (B), and (C), (see Section 4.2) respectively. $\alpha$-tocopherol (1), $\alpha$-tocopheryl acetate (2), phylloquinone (3), and menaquinone-4 (4). To compare resolution in problematic segment in Figure $4 \mathrm{~A}, \mathrm{~B}$, a zoom $(\times 10)$ is plotted. The NIST library values for $\alpha$-tocopherol, $\alpha$-tocopheryl acetate and phylloquinone were 830,850 , and 813 , respectively. The insets show the spectra acquired in the samples (up) compared to those of the NIST library (down).

\section{Materials and Methods}

\subsection{Chemicals}

All chemicals used were supplied by Sigma-Aldrich (Milan, Italy) and were analytical grade. The standard of vitamins E (DL- $\alpha$-tocopherol), E acetate (DL- $\alpha$-tocopheryl acetate), K1 (phylloquinone) and $\mathrm{K} 2$ (menaquinone-4) have a purity level greater than $96 \%$. Vitamin stock solutions $\left(0.4 \mathrm{mg} \mathrm{mL}^{-1}\right)$ were made in $50 \%(v / v)$ acetonitrile in ethanol and stored in aliquots $(0.5 \mathrm{~mL})$ at $-20{ }^{\circ} \mathrm{C}$ in the dark. More dilute working solutions were obtained just before use in the range $0.05-150 \mu \mathrm{g} \mathrm{mL}-\mathrm{SPME}$ working solutions were prepared in water with $10 \%$ ethanol, $\mathrm{HCl}(10 \mathrm{mM})$ just before use.

\subsection{Sample Pre-Treatment}

Vitamins were extracted from vegetables using three different approaches. All samples were always added with the internal standard before the sample pretreatment. In the first approach (A), each sample ( $1 \mathrm{~g}$ of fresh or $0.1 \mathrm{~g}$ of dry sample) was homogenized (Ultra Turbax IKA T18 Basic) (Merck 
Life Science S.r.l. 20149 Milano Italy) with $10 \mathrm{~mL}$ of water and $0.4 \mathrm{~mL}$ of $200 \mu \mathrm{g} \mathrm{mL}-1$ menaquinone (internal standard) at the speed of $15.000 \mathrm{rpm}$ for $1 \mathrm{~min}$, after which, $15 \mathrm{~mL}$ of $6 \%(v / v)$ 2-propanol in hexane was added. The mixture was vortexed for $1 \mathrm{~min}$ and centrifuged (ALC Multispeed Refrigerated Centrifuge PK 121R) (Universal Resource Trading LTD, United Kingdom) at 3500 rpm for 5 min at $21^{\circ} \mathrm{C}$. The organic phase was then recovered and dried under a gentle stream of the residue was dissolved in $0.4 \mathrm{~mL}$ of pure hexane and $1 \mu \mathrm{L}$ was injected in the GC-MS system.

For the second extraction procedure (B), each sample ( $1 \mathrm{~g}$ of fresh or $0.1 \mathrm{~g}$ of dry sample) was subjected to a solid-liquid extraction (30 min at room temperature in the dark) with $10 \mathrm{~mL}$ of $50 \%$ $(v / v)$ acetonitrile in ethanol with $0.1 \%(w / v)$ butylated hydroxy anisole and $0.4 \mathrm{~mL}$ of internal standard under magnetic stirring. Then, the mixture was centrifuged for $5 \mathrm{~min}$ at $3500 \mathrm{rpm}$; the supernatant was transferred into an amber tube containing $0.25 \mathrm{~g}$ of $\mathrm{Na}_{2} \mathrm{SO}_{4}$ anhydrous, briefly shaken and $1 \mu \mathrm{L}$ injected.

The third procedure was based on SPME (C). Samples ( $0.075 \mathrm{~g}$, fresh or dry) were placed in $15 \mathrm{~mL}$ amber vials, weighed and $15 \mathrm{~mL}$ of water with $10 \%(v / v)$ ethanol, $\mathrm{HCl}(10 \mathrm{mM})$ and $30 \mu \mathrm{L}$ of internal standard were added. The solution was stirred for $15 \mathrm{~min}$ at $50{ }^{\circ} \mathrm{C}$, and finally subjected to SPME for $30 \mathrm{~min}$ at $50^{\circ} \mathrm{C}$ under magnetic stirring. Desorption of the analytes was performed into the GC injector kept at the constant temperature of $300^{\circ} \mathrm{C}$ in splitless mode with 5 min of sampling time. The fiber was removed from the injector after $8 \mathrm{~min}$, clean and ready for the next extraction. Quantifications were based on internal standard method. The matrix effect on the SPME was calculated [28] as follows. Different amounts ( $1.5 \mathrm{~g}, 0.15 \mathrm{~g}$ or $0.075 \mathrm{~g}$ ) of vegetable samples were placed in $15 \mathrm{~mL}$ amber vials, spiked with the analytes at the concentration level of $100 \mu \mathrm{g} \mathrm{g}^{-1}$ and added with $15 \mathrm{~mL}$ of the extraction solution. Each sample was mixed for $15 \mathrm{~min}$ at $50^{\circ} \mathrm{C}$ before being subjected to SPME-GC-MS analysis. Matrix effects were calculated by comparing the area responses obtained for each dilution ratio (1:1 or $0.1: 1$ or $0.005: 1, w / v)$, with standard solutions at the corresponding concentrations as a reference

\subsection{Apparatus}

The gas chromatography-mass spectrometry system consisted of a Finnigan Trace GC Ultra gas chromatograph equipped with a split/splitless programmed temperature vaporization (PTV) injector coupled to an ion trap mass spectrometer (FinniganPolarisQ A TRACE TM TR-5 GC Column (Thermo Fisher Scientific Milan, Italy) (30 m, $0.25 \mu \mathrm{m}$ i.d., $0.25 \mu \mathrm{m}$ film thickness, Thermo Fisher Scientific, Milan, Italy) was used with helium as carrier gas (flow rate $1 \mathrm{~mL} \mathrm{~min}^{-1}$ ). The injector i.d. was $1 \mathrm{~mm}$. The oven temperature program was $3 \mathrm{~min}$ at $180{ }^{\circ} \mathrm{C}$, from 180 to $300^{\circ} \mathrm{C}$ at $25^{\circ} \mathrm{C} \mathrm{min}^{-1}$, and $13 \mathrm{~min}$ at $300^{\circ} \mathrm{C}$. When working with direct injection, the injector worked in PTV splitless mode, to avoid thermal degradation and/or adsorption. The relevant parameters are reported in Table 6. For SPME, the injector temperature and the GC transfer line were both set at $30{ }^{\circ} \mathrm{C}$. The mass spectrometer was operated in the electron impact positive ion mode with a source temperature of $250{ }^{\circ} \mathrm{C}$. The electron energy was $70 \mathrm{eV}$ and the filament current $250 \mu \mathrm{A}$. Mass spectra were acquired in the $\mathrm{m} / \mathrm{z}$ range 50 -Detection of the vitamins were made from extracted ion chromatograms $(\mathrm{m} / \mathrm{z} 165$, for vitamin $\mathrm{E}$ and E acetate, and 186 and 225 for K1 and K2, respectively) obtained in total ion current (TIC) mode.

Table 6. Operative parameters of programmed temperature vaporization (PTV) splitless injection.

\begin{tabular}{ccccc}
\hline Injection Phase & Pressure (KPa) & Rate $\left({ }^{\circ} \mathbf{C} / \mathbf{s e c}\right)$ & Temperature $\left({ }^{\circ} \mathbf{C}\right)$ & Time $(\mathbf{m i n})$ \\
\hline injection & 83 & & 70 & 0.15 \\
evaporation & 83 & 6.7 & 100 & 0.3 \\
transfer & 210 & 14.5 & 270 & 1 \\
cleaning & & 14.5 & 300 & 3 \\
\hline
\end{tabular}

\section{Conclusions}

In conclusion, although the benefits of SPME (high productivity and low solvent consumption) are well known in academic research, the technology is not yet used as widely as it should by regulatory agencies, perhaps due to the perception that quantitative analysis is not solid. as much as traditional 
techniques. In this study, however, the equivalence of the non-exhaustive SPME with the exhaustive extractions of the conventional SLE and LLE techniques is demonstrated. Sample preparation is much simpler $(0.075 \mathrm{~g}$ of sample in $15 \mathrm{~mL}$ of water with $10 \%$ ethanol) and faster (extraction time with the fiber of only $30 \mathrm{~min}$, fully automatic) compared to the other two conventional procedures. Gas chromatography-mass spectrometry (GC-MS) was employed for first time for the analysis of $\alpha$-tocopherol, $\alpha$-tocopheryl acetate and phylloquinone in vegetables samples (onion, carrot, celery, and curly kale) using menaquinone- 4 as the internal standard. Samples were extracted using different pre-treatment methods, i.e., (A) solid-liquid-liquid-liquid extraction (SLE-LLE), (B) SLE, and (C) SPME. Even if all the approaches allowed the determination of the analytes in the selected samples, SPME procedure provided the best performances, together with a reduced use of solvent, time consumption, and experimental complexity. In summary, in this manuscript a good proof-of-concept report of the combination of different methods with a high-throughput and "green" sample preparation approach is reported. This approach could be extended to more target compounds and more Vitamins (Vitamin A for instance) in future work.

Author Contributions: Conceptualization C.Z.; methodology and validation A.A.; formal analysis, G.M.; data curation, P.C.; writing-original draft preparation, C.Z.; writing-review and editing, F.C. and C.F.; visualization, I.R.R.; supervision, M.Q. and M.L.C. All authors have read and agreed to the published version of the manuscript.

Funding: This research was funded by: The AGER 2 Project, grant n. 2016-0174, AGER Foundation-Olive Tree and Oil: Competitive-Claims of olive oil to improve the market value of the product; EU project 820587-OLIVE-SOUND-Ultrasound reactor-The solution for a continuous olive oil extraction process H2020-EU.2.1.-INDUSTRIAL LEADERSHIP-EIC-FTI-2018-2020-Fast Track to Innovation (FTI)-European Union's Horizon 2020 research and innovation program under grant agreement No. 820587.

Conflicts of Interest: The authors declare no conflict of interest.

\section{References}

1. Krutz, L.J.; Senseman, S.A.; Sciumbato, A. Solid-phase microextraction for herbicide determination in environmental samples. J. Chromatogr. A 2003, 999, 103-121. [CrossRef]

2. Godage, N.H.; Gionfriddo, E. A critical outlook on recent developments and applications of matrix compatible coatings for solid phase microextraction. TrAC Trends Anal. Chem. 2019, 111, 220-228. [CrossRef]

3. Zingg, J.-M. Vitamin E: An overview of major research directions. Mol. Asp. Med. 2007, 28, 400-422. [CrossRef]

4. Zingg, J.-M.; Meydani, M.; Azzi, A. $\alpha$-Tocopheryl phosphate-An activated form of vitamin E important for angiogenesis and vasculogenesis? BioFactors 2012, 38, 24-33. [CrossRef]

5. Ferland, G. Vitamin K and the Nervous System: An Overview of its Actions. Adv. Nutr. 2012, 3, $204-212$. [CrossRef] [PubMed]

6. European Commission. Regulation EC No. 1924/2006 on Nutrition and Health Claims Made on Foods. Off. J. Eur. Union 2012, L310. Available online: https://eur-lex.europa.eu/legal-content/EN/TXT/PDF/?uri=CELEX: 02006R1924-20121129\&from=EN (accessed on 4 April 2019).

7. European Commission. Regulation EC No. 432/2012 Establishing a List of Permitted Health Claims Made on Foods, Other than those Referring to the Reduction of Disease Risk and to Children's Development and Health. Off. J. Eur. Union 2012, L136. Available online: https:/eur-lex.europa.eu/legal-content/EN/TXT/PDF/ ?uri=CELEX:32012R0432\&from=EN (accessed on 11 February 2019).

8. Roselli, L.; Clodoveo, M.L.; Corbo, F.; De Gennaro, B. Are health claims a useful tool to segment the category of extra-virgin olive oil? Threats and opportunities for the Italian olive oil supply chain. Trends Food Sci. Technol. 2017, 68, 176-181. [CrossRef]

9. Harshman, L.C.; Drake, C.G.; Wargo, J.A.; Seliger, B.; Bhardwaj, N. Cancer Immunotherapy Highlights from the 2014 ASCO Meeting. Cancer Immunol. Res. 2014, 2, 714-719. [CrossRef] [PubMed]

10. Kramps, T.; Probst, J. Messenger RNA-based vaccines: Progress, challenges, applications. Wiley Interdiscip. Rev. RNA 2013, 4, 737-749. [CrossRef] [PubMed]

11. Leonard, S.W.; Traber, M.G. Methods for assessment of Vitamin E. In Laboratory Assessment of Vitamin Status; Elsevier BV: Oxford, UK, 2019; pp. 79-105. 
12. Beldean-Galea, M.S.; Horga, C.; Coman, M.V. Separation and determination of tocopherols in vegetable oils by solid phase extraction on porous polymers SPE cartridges and capillary gas chromatography analysis. Open Chem. 2010, 8, 1110-1116. [CrossRef]

13. Grigoriadou, D.; Androulaki, A.; Psomiadou, E.; Tsimidou, M.Z. Solid phase extraction in the analysis of squalene and tocopherols in olive oil. Food Chem. 2007, 105, 675-680. [CrossRef]

14. Sunarić, S.; Lalić, J.; Spasić, A. Simultaneous Determination of Alpha-Tocopherol and Alpha-Tocopheryl Acetate in Dairy Products, Plant Milks and Health Supplements by Using SPE and HPLC Method. Food Anal. Methods 2017, 10, 3886-3901. [CrossRef]

15. Viñas, P.; Bravo-Bravo, M.; López-García, I.; Pastor-Belda, M.; Hernández-Córdoba, M. Pressurized liquid extraction and dispersive liquid-liquid microextraction for determination of tocopherols and tocotrienols in plant foods by liquid chromatography with fluorescence and atmospheric pressure chemical ionization-mass spectrometry detection. Talanta 2014, 119, 98-104. [CrossRef] [PubMed]

16. Aresta, A.; Di Grumo, F.; Zambonin, C. Determination of Major Isoflavones in Soy Drinks by Solid-Phase Micro Extraction Coupled to Liquid Chromatography. Food Anal. Methods 2015, 9, 925-933. [CrossRef]

17. Aresta, A.; Zambonin, C. Determination of $\alpha$-Tocopherol in Olive Oil by Solid-Phase Microextraction and Gas Chromatography-Mass Spectrometry. Anal. Lett. 2017, 50, 1580-1592. [CrossRef]

18. Calvello, R.; Aresta, A.; Trapani, A.; Zambonin, C.; Cianciulli, A.; Salvatore, R.; Clodoveo, M.L.; Corbo, F.; Franchini, C.; Panaro, M.A. Bovine and soybean milk bioactive compounds: Effects on inflammatory response of human intestinal Caco-2 cells. Food Chem. 2016, 210, 276-285. [CrossRef]

19. Salvo, A.; La Torre, G.L.; Rotondo, A.; Mangano, V.; Casale, K.E.; Pellizzeri, V.; Clodoveo, M.L.; Corbo, F.; Cicero, N.; Dugo, G. Determination of Squalene in Organic Extra Virgin Olive Oils (EVOOs) by UPLC/PDA Using a Single-Step SPE Sample Preparation. Food Anal. Methods 2016, 10, 1377-1385. [CrossRef]

20. Sadrykia, F.; Shayanfar, A.; Valizadeh, H.; Nemati, M. A Fast and Simple Method for Determination of Vitamin E in Infant Formula by Dispersive Liquid-Liquid Microextraction Combined with HPLC-UV. Food Anal. Methods 2018, 12, 23-31. [CrossRef]

21. Górska, R.M. Methods for assessment of Vitamin K. In Laboratory Assessment of Vitamin Status; Elsevier BV: Oxford, UK, 2019; pp. 107-147. [CrossRef]

22. Huo, J.Z.; Nelis, H.J.; Lavens, P.; Sorgeloos, P.; De Leenheer, A.P. Simultaneous determination of $\alpha$-tocopheryl acetate and tocopherols in aquatic organisms and fish feed. J. Chromatogr. B: Biomed. Sci. Appl. 1999, 724, 249-255. [CrossRef]

23. Xiao, Z.; Lester, G.E.; Luo, Y.; Wang, Q. Assessment of Vitamin and Carotenoid Concentrations of Emerging Food Products: Edible Microgreens. J. Agric. Food Chem. 2012, 60, 7644-7651. [CrossRef] [PubMed]

24. Viñas, P.; Bravo-Bravo, M.; López-García, I.; Hernández-Córdoba, M. Dispersive liquid-liquid microextraction for the determination of vitamins $\mathrm{D}$ and $\mathrm{K}$ in foods by liquid chromatography with diode-array and atmospheric pressure chemical ionization-mass spectrometry detection. Talanta 2013, 115, 806-813. [CrossRef] [PubMed]

25. Tarvainen, M.; Fabritius, M.; Yang, B. Determination of vitamin K composition of fermented food. Food Chem. 2019, 275, 515-522. [CrossRef] [PubMed]

26. Pokkanta, P.; Sookwong, P.; Tanang, M.; Setchaiyan, S.; Boontakham, P.; Mahatheeranont, S. Simultaneous determination of tocols, $\gamma$-oryzanols, phytosterols, squalene, cholecalciferol and phylloquinone in rice bran and vegetable oil samples. Food Chem. 2019, 271, 630-638. [CrossRef]

27. Reto, M.; Figueira, M.E.; Mota-Filipe, H.; Almeida, C.M.M. Analysis of vitamin K in green tea leafs and infusions by SPME-GC-FID. Food Chem. 2007, 100, 405-411. [CrossRef]

28. Dubbs, M.D.; Gupta, R.B. Solubility of Vitamin E ( $\alpha$-Tocopherol) and Vitamin K3(Menadione) in Ethanol-Water Mixture. J. Chem. Eng. Data 1998, 43, 590-591. [CrossRef]

29. Aresta, A.; Calvano, C.D.; Trapani, A.; Zambonin, C.; De Giglio, E. $\alpha$-Tocopherol/chitosan-based nanoparticles: Characterization and preliminary investigations for emulsion systems application. J. Nanoparticle Res. 2014, 16, 2230. [CrossRef] 
30. Zambonin, C.; Quinto, M.; De Vietro, N.; Palmisano, F. Solid-phase microextraction—Gas chromatography mass spectrometry: A fast and simple screening method for the assessment of organophosphorus pesticides residues in wine and fruit juices. Food Chem. 2004, 86, 269-274. [CrossRef]

Sample Availability: Not available.

(C) 2020 by the authors. Licensee MDPI, Basel, Switzerland. This article is an open access article distributed under the terms and conditions of the Creative Commons Attribution (CC BY) license (http://creativecommons.org/licenses/by/4.0/). 